\title{
The present and future of smart power grid in developing countries
}

\begin{abstract}
Strong and huge interests on smart grid have increased extensively in recent years around the world. This scenario could be a promising reason for future research in this area. This next form of electricity grid will be able to manage various parts of power production from power plants to the customers. Smart grid has become a major challenge in developed nations in both research and utilization aspects. On the other side, application of smart grid in developing countries is still lagging behind as compared to the developed ones. However, most of developing nations are currently investigating potentials of some pilot projects or few research works. In this article, the applied activities in developing countries for smart grid are reviewed and categorized into two major groups: group of pioneer developing countries in smart grid and other developing countries are placed in another group. The findings demonstrate that a few countries such as China, India and Brazil have had proper planning and development in this technology. In some cases like China, the efforts are considered comparable with developed nations like U.S. Therefore, according to the development progress for smart grid in China, India and Brazil, a pattern of reference for other developing countries is suggested.
\end{abstract}

Keyword: Smart grid; Developing countries; Renewable energy; Power grid 